\title{
PAISAJES DEL AGUA Y TURISMO FLUVIAL EN LA RAYA IBÉRICA
}

\author{
Antonio-José Campesino Fernández \\ Universidad de Extremadura
}

\section{RESUMEN}

En su discurso de $1.292 \mathrm{~km}$ lineales con $138.000 \mathrm{~km}^{2}$ superficiales, la frontera (Raya/ Raia) ibérica atraviesa los paisajes atlántico-mediterráneos más representativos del Oeste peninsular compartido, avenados por los colectores fluviales internacionales del Miño, Duero, Tajo y Guadiana, que ensamblan el solar ibérico y articulan la frontera interior más antigua de la Unión Europea (1267). El agua, factor básico de organización del territorio fronterizo (poblamiento, defensa y relación), -tras los desencuentros de la planificación hidrológica peninsular-, amplía su funcionalidad desde mediados de los años noventa con las políticas de cooperación transfronteriza, como recurso natural estratégico de enorme atractivo y potencial de futuro, para la oferta de productos turísticos náuticos en el nuevo destino de la Raya ibérica hispano-lusa, como hemos constatado en el Proyecto de Investigación TURFRONT (2012-2014) ${ }^{1}$

Palabras clave: frontera, agua, turismo, recursos, productos.

\section{ABSTRACT}

Water landscapes and tourism in the iberian border

In his $1.292 \mathrm{~km}$ linear with $138.000 \mathrm{~km}^{2}$ surface, the border (Raya / Raia) traverses the most representative Iberian-Atlantic Mediterranean shared peninsular west, landscapes drained by international river collectors, Miño, Douro, Tagus and Guadiana, joining

1. Proyecto TURFRONT (2012-2014): «Dinámica, situación actual y análisis prospectivo del 'Turismo de Frontera (2000-2020)», como motor de desarrollo territorial de la Raya ibérica: definición de la oferta, caracterización de la demanda y repercusiones económicas». Ref. Proyecto CSO2011-29529-C04, Subproyectos CSO2011-29529-C04-01 y CSO201129529-C04-03. Plan Nacional I+D+i. Proyectos de Investigación Fundamental. Entidades financiadoras: Ministerio de Economía y Competitividad y Fondo Europeo de Desarrollo Regional. Investigador Principal: Antonio-José Campesino Fernández. 
Iberian sun and articulate the oldest inner border of the European Union (1267). Water core organizing the border territory (settlement, defense and related), -after disagreements of peninsular water planning-, since the mid-nineties with the policies CBC expands its functionality as a strategic natural resource, enormous attractive and future potential for the supply of nautical tourism products in the new destination for SpanishPortuguese Iberian Raya, as we have seen in TURFRONT Research Project (2012-2014.

Keywords: Border, water, tourism, resources, products.

\section{AGUA, FRONTERA Y TURISMO}

En la historia urbana y del poblamiento los ríos ejercieron siempre una atracción especial, como imanes de fijación de personas y actividades múltiples en sus orillas, personalizando ciudades y territorios. Las estrechas relaciones causales entre agua, poblamiento y urbanización confieren a los paisajes del agua, naturales y humanizados, un papel relevante en cualquier propuesta de desarrollo territorial de municipios, regiones y países (Ribas, 2006).

A la hora de la fijación de límites soberanos entre países y regiones, las cuencas fluviales asociadas a la topografía (aguas vertientes) fueron elementos nítidos de diferenciación, hasta alcanzar en las fronteras húmedas estatales su mayor protagonismo, como elementos geográficos de separación de soberanías nacionales. Sin embargo, esta presunta ruptura fue siempre más política que real, porque la frontera divisoria en los mapas internacionales, al trazarse en medio de los cauces con signos convencionales de cruces y rayas sin obstáculo físico separador, concedía a los Estados un reparto equitativo y compartido del agua en ambas márgenes.

Distintas han sido las percepciones históricas de las fronteras fluviales. Los Estados las entendieron como barreras naturales para defensa de la soberanía y control del territorio, más teórico que real, para «mantener a raya» al enemigo y a los propios lugareños. En cambio, los habitantes de la frontera, ajenos a las estrategias políticas y sujetos pacientes de las mismas, compartieron realmente los ríos y las formas comunes de vida a ellos asociadas en los largos períodos de tranquilidad entre conflictos bélicos. Ser rayano imprimió siempre carácter, por la existencia de intereses vitales y fatigas comunes, ajenas a las de sus gobernantes, mutando la función militar separadora por la civilizada comercial de una Raya que, lejos de separar territorios y pueblos de características geográficas comunes, los unía con estrechos lazos de consanguinidad, como bien me enseñó mi maestro don Ángel Cabo (Cabo, 1996).

El trazado de la Raya ibérica, la más antigua (1267) y dilatada $(1.292 \mathrm{~km})$ de las fronteras interiores de la Unión Europea, atraviesa las unidades paisajísticas, atlántico-mediterráneas más representativas del occidente peninsular: cursos de 
agua (Miño, Duero, Tajo y Guadiana), macizos montañosos, valles asociados y penillanuras adehesadas, naturaleza compartida -lo que el Dios Sabio unió, el hombre necio se empeñó en separar- que ensambla fuertemente el solar ibérico, como bien me enseñó el maestro portugués de geógrafos Orlando Ribeiro (Ribeiro, 1980).

La frontera ibérica, defensiva, represiva y militarizada, inicia su proceso de obsolescencia con la desaparición paralela de los fascismos peninsulares (Revolução dos Cravos, 1974 y Transición democrática española, 1975), liquidándose - presuntamente- con la incorporación de España y Portugal a la Europa Comunitaria el 1 de enero de 1986. Pese a ello, hasta casi una década después no se inició la Cooperación Transfronteriza de Primera Generación (1992-2013), gracias a los Programas Operativos INTERREG. Resultó fácil, desde Bruselas, exigir el hermanamiento por decreto y la presunta liquidación de la Raya, tras cuatrocientos años de «costas tornadas» y desencuentros bélicos y políticos del iberismo peninsular (Cabero, 2002).

El turismo se ha significado como uno de los sectores clave de la cooperación, pero no será hasta 2007 cuando abordamos la investigación sobre el «Turismo de Frontera» (Campesino, Dir. 2007), que materializamos en el Proyecto TURFRONT (2012-2014) (Campesino, Dir. 2013). El agua de los cuatro grandes ríos ha superado ya su pasiva concepción separadora de la frontera hispano-lusa, para convertirse en recurso natural y producto turístico de enorme atractivo y potencial de ocio y disfrute, con imagen de marca internacional, significándose como objetivo estratégico de la Cooperación Transfronteriza de Segunda Generación (2014-2020), dentro del Programa Operativo INTERREG V-A.

\section{PAisAJeS PATRIMONIALES DEl AGUA EN LA RAYA IBÉRICA}

Hasta fechas recientes, las relaciones causales entre agua y paisaje estuvieron ausentes en las políticas públicas interestatales. La inserción de ambos países ibéricos en la Unión Europea, con la obligada cooperación transfronteriza antedicha, y la Nueva Cultura del Territorio (Cog, 2006), con la inserción de la cuestión paisajística en la planificación territorial y en el planeamiento urbanístico, han permitido la consideración de los paisajes del agua como patrimonios culturales (Mata y Fernández, 2010).

De los valiosos recursos paisajísticos de la Raya ibérica sobresalen por su valor patrimonial los Espacios Naturales Protegidos de las regiones/regiões fronterizas de Castilla y León/Trás-os-Montes/Beira Interior Norte; Extremadura/ Alentejo/Região Centro, y Andalucía onubense/Baixo Alentejo/Algarve), ligados a las dilatadas láminas de agua de las cuencas hidrográficas de los ríos Duero, Tajo y Guadiana, actualmente en proceso de transformación de recursos 
en productos turísticos y en destinos transfronterizos con aprovechamientos náuticos de tipología fluvial y lacustre.

\section{Castilla y León-Trás-os-Montes-Beira Interior Norte/Alto Douro}

La Raya del Duero se extiende por $349 \mathrm{~km}$ de las provincias de Zamora (179 $\mathrm{km})$ y de Salamanca $(170 \mathrm{~km})$, sobre territorio de 37 términos municipales con superficie de $2.366,2 \mathrm{~km}^{2}$.

\section{Parque Natural del Lago de Sanabria y alrededores}

Situado en el territorio fronterizo del NE zamorano, colindante con la provincia de Orense en las estribaciones de las sierras Cabrera y Segundera, se ubica el excepcional paisaje glaciar del Lago de Sanabria y entorno, reconocido desde 1946 con distintas declaraciones patrimoniales hasta la definitiva de Parque Natural del Lago de Sanabria ${ }^{2}$, para preservar la morfología glaciar cuaternaria, su riqueza florística y faunística y la calidad de sus aguas. Ocupa una superficie de 22.365 has, incluyendo cuatro términos municipales (Galende, Cobreros, Trefacio y Porto) y 29 núcleos de población con 805 habitantes. En su interior, avenado por el río Tera, se localiza el Lago de Sanabria, de 368,5 has $(3 \mathrm{~km}$ de largo por $1,5 \mathrm{~km}$ de ancho y $53 \mathrm{~m}$ de profundidad) el mayor lago natural y glaciar de la península ibérica con sus 20 lagunas, en cotas altitudinales entre $997 \mathrm{~m}$ del nivel del agua y $2.124 \mathrm{~m}$ de Peña Trevinca.

\section{Parques Naturales de Las Arribes del Duero y Douro Internacional}

El tramo de $122 \mathrm{~km}$ de la «raya húmeda» del Duero y sus afluentes Huebra, Tormes, Águeda, Las Uces y Esla se encuentra repartido entre las provincias de Zamora (1/3) y Salamanca (2/3). Es un territorio de notable singularidad paisajística por los marcados contrastes entre penillanuras y valles fluviales encajados en profundos cañones (arribes o arribas) con cantiles verticales de hasta $400 \mathrm{~m}$.

Sus excepcionales condiciones geológicas, geomorfológicas, micro-climáticas y biogeográficas han condicionado históricamente las formas de poblamiento y la actividad económica de estos enclaves rayanos, hasta ser reconocidas y

2. Orden Ministerial de 7 de febrero de 1946, del Ministerio de Agricultura, por la que se declara «Sitio Natural de Interés Nacional». Declaración de «Paisaje Pintoresco» en 1953. Real Decreto 30161/1978, de 27 de octubre, de declaración del Parque Natural del Lago de Sanabria y alrededores (BOE n. ${ }^{\circ} 310$, de 28 de diciembre de 1978), modificado por el D. 122/1985, de 12 de septiembre; ampliado en sus límites y regulada su organización por D. 121/1990 de 5 de junio, y dotado del Plan de Ordenación de los Recursos Naturales del Espacio Natural «Lago de Sanabria y alrededores», por D. 62/2013, de 26 de septiembre (BOC y L n. ${ }^{\circ}$ 190, de 2 de octubre de 2013). 
protegidas por las declaraciones de los Parques Naturales de Las Arribes del Duero y del Douro Internacional ${ }^{3}$. Ambos espacios protegidos se encuentran insertos dentro de la Red Natura 2000, como Zona de Especial Protección de Aves (ZEPA) y Lugar de Interés Comunitario (LIC).

Las Arribes del Duero (Salamanca-Zamora) fueron declaradas Parque Natural el 22 de abril de $2002^{4}$, afectando a 106.500 has con 51 núcleos de población ${ }^{5}$ y 17.000 habitantes (Hortelano, 2014). El Parque Natural do «Douro Internacional» fue declarado en $1998^{6}$, con una superficie protegida de 85.150 has entre los ríos Duero y Águeda, que afecta a los concelhos portugueses de Figueira de Castelo Rodrigo, Freixo de Espada à Cinta, Miranda do Douro y Mogadouro.

\section{Extremadura-Alentejo-Região Centro}

El vínculo existente entre la frontera y las dos grandes cuencas hidrográficas de Extremadura, Tajo y Guadiana, que atraviesan la Comunidad de $\mathrm{E}$ a $\mathrm{O}$ y penetran en Portugal, es muy estrecho. Ambas cuencas hidrográficas se encuentran muy reguladas por embalses de gran capacidad y aprovechamiento hidroeléctrico y de regadío (Campesino, 2001; 2013; 2015).

En la dilatada raya extremeña, de $420 \mathrm{~km}$ lineales, pese a la escasez de productos turísticos (Dirección General de Acción Exterior, 2015), hay dos productos transfronterizos, ligados al agua de los ríos Tajo y Guadiana, que sobresalen ya por su atractivo y potencial de futuro: el Parque Natural Tajo/Tejo Internacional, y el Guadiana Internacional. Ambos, vinculados a la enorme superficie de agua embalsada, con más de un millar de kilómetros de costa dulce interior, constituyen la réplica meridional al Parque Natural de Las Arribes del Duero y Douro Internacional.

3. La delimitación de la frontera internacional y las aguas compartidas del Duero entre España y Portugal fueron pactadas en el Tratado de Lisboa de 1864: «Entrará el río Duero cerca de la confluencia del arroyo Castro. Desde este punto, la línea internacional irá por el centro de la corriente principal del Duero hasta su confluencia con el Águeda, por cuyas aguas remontará hasta su unión con el Tormes».

4. Ley 5/2002, de 11 de abril, de declaración de Parque Natural de Arribes del Duero (SalamancaZamora) (BOC y L n. ${ }^{\circ} 79$, de 26 de abril, de 2002).

5. Al Parque Natural pertenecen los siguientes términos municipales: 13 zamoranos (Argañín, Fariza, Fermoselle, Fonfría, Gamones, Moral de Sayago, Moralina, Pino, Torregamones, Villadepera, Villarcampo, Villar del Buey y Villardiegua de la Ribera) y 24 salmantinos (Ahigal de los Aceiteros, Aldeadávila de la Ribera, Almendra, Barruecopardo, Bermellar, La Bouza, Cabeza de Caballo, Cerezal de Peñahorcada, La Fregeneda, Hinojosa del Duero, Lumbrales, Masuedo, Mieza, La Peña, Preña, Puerto Seguro, Saldeana, San Felices de los Gallegos, Saucelle, Sobradillo, Trabanca, Vilvestre, Villarino de los Aires y Zarza de la Pumareda).

6. Decreto-Lei n. ${ }^{\circ} 8 / 98$, de 11 de mayo, de declaração do Parque Natural do «Douro Internacional» (PNDI). 


\section{Parque Natural Tajo/Tejo Internacional}

De los $1.009 \mathrm{~km}$ de recorrido peninsular del Tajo, $226 \mathrm{~km}$ corresponden a tierras portuguesas, sirviendo $49 \mathrm{~km}$ de frontera internacional. Un territorio de poblamiento secular que se refleja en el proceso de humanización del paisaje y en el patrimonio construido. Al rayano río Tajo ${ }^{7}$ vierten los afluentes (Erjas, Sever y Salor; Ponsul y Aravil) y se represa en los embalses de Alcántara y Cedillo. Pese a su extrema regulación, que merma su potencial navegable -el Tajo únicamente lo es a partir del Puente Romano de Alcántara- estas tablas mansas de agua poseen atractivo y potencialidad turística, como soporte de actividades acuáticas recreativas: barco turístico para cruceros fluviales, observación ornitológica y florística, gastronomía, cultura, senderismo, deporte y aventura. La potencial capacidad de atracción turística de los dos ríos queda avalada por la existencia de dos proyectos turísticos de gran envergadura que trabajan en esta dirección:

El Espacio Natural «Tajo Internacional y Riberos» ${ }^{8}$, ubicado al SO de la provincia de Cáceres y compartido con el distrito beirense de Castelo Branco y el alentejano de Portalegre, fue reconocido como ZEPA en 2000, año en que la orilla portuguesa fue declarada Parque Natural Tejo Internacional. Años después, en 2006, la parte extremeña de unos $85 \mathrm{~km}$ se convirtió en Parque Natural «Tajo Internacional» ${ }^{9}$. Los fundamentos patrimoniales se contienen en los riberos del Tajo, con laderas de fuertes pendientes, condicionadas por el microclima, cubiertas de vegetación de monte adehesado (encinas, alcornoques, acebuches, carballos) y denso matorral atlántico-mediterráneo (retamares, alisedas, saucedas, tamujares). Alto valor ecológico el de estos enclaves privilegiados por la variedad florística y sus especies endémicas, como el lirio amarillo (Iris lusitanica) y la orquídea (Serapia verde), y la diversidad faunística de 276 especies de vertebrados protegidos en peligro de extinción, grandes rapaces (cigüeña negra -22 parejas-, alimoche -32 parejas-, buitre negro -40 parejas-, águila real -12 parejas-, águila imperial ibérica, perdicera, calzada, culebrera, pescadora), así como ciervos, jabalíes y otras especies (nutrias, lagartos...). (Diputación de Cáceres, 2011).

El P. N. se extiende linealmente a lo largo de una decena de kilómetros entre el Puente Romano de Alcántara y la presa de Cedillo, avenado por el río

7. El nombre Tajo, proviene del término romano «Tagus», derivado del latino «taliare», como sinónimo de tallar o cortar, tarea geológica que este río ha venido haciendo sobre el sustrato pizarroso paleozoico hasta labrar su fosa encajada.

8. Decreto 187/2005, de 26 de julio, por el que se aprueba el Plan de Ordenación de los Recursos Naturales del Espacio Natural «Tajo Internacional». Decreto 176/2006, de 17 de octubre, por el que se modifica el Decreto 187/2005, de 26 de julio. Decreto 10/2001, de 4 de febrero, por el que se modifica el Decreto 187/2005.

9. Ley 1/2006, de 7 de julio, de la Presidencia de la Junta de Extremadura, por la que se declara el Parque Natural del «Tajo Internacional». 
Tajo y sus afluentes. Cuenta con una superficie total transfronteriza de 48.582 has, de las que 25.088 has, pertenecen a Extremadura y afecta a once términos municipales extremeños (Alcántara, Brozas, Carbajo, Cedillo, Herrera de Alcántara, Membrío, Salorino, Herreruela, Santiago de Alcántara, Valencia de Alcántara y Zarza la Mayor) y nueve portugueses (Castelo Branco, Idanhaa-Nova, Penamacor, Vila Velha de Rodão, Nisa, Castelo de Vide, Portalegre, Marvão y Gavião).

Seis años después, la cooperación transfronteriza España-Portugal fraguó en el acuerdo de creación del Parque Natural Tajo/Tejo Internacional ${ }^{10}$, primer Parque Natural internacional de la Unión Europea con elevados niveles de protección ambiental (Red Natura 2000, ZEPA, LIC). Desde junio de 2014, la Comisión de Planificación y Desarrollo del Parque Internacional Tajo/Tejo (PITT), está preparando la candidatura conjunta de solicitud ante el Comité MaB de la UNESCO como «Reserva de la Biosfera Parque Internacional Tajo/Tejo», que afectaría a 400.000 hectáreas y comprendería, además de los dos Parques Naturales, un total de 20 espacios de la Red Natura 2000, para integrarse en la Red Mundial de Reservas de la Biosfera.

El Proyecto de Cooperación Transfronteriza Tajo/Tejo Internacional www. turismotajointernacional.com persigue la conformación del destino turístico Taejo Internacional, mediante el diseño y conjugación de diferentes productos turísticos (de naturaleza -navegabilidad del Tajo-, observación de fauna -berrea-y flora, gastronomía, cultura y senderismo) (Medel, 2013). En el último cuatrienio se llevan invertidos $2.581 .800 €$ en proyectos de conservación (Cruz, 2014). Con la aprobación del Plan Rector de Uso y Gestión (PRUG) del Parque Natural Tajo Internacional se está tramitando la candidatura como Reserva de la Biosfera que, de lograrse, reforzaría la promoción de la Raya ibérica como destino turístico internacional, con implicación de dos Estados, tres regiones y 20 municipios rayanos, extremeños y portugueses.

\section{Parque Temático Natural de Alqueva: Guadiana Internacional}

Durante los $818 \mathrm{~km}$ de recorrido (578 en España y 140 en Portugal) el Guadiana ocupa una cuenca de $67.733 \mathrm{~km} 2$ (81,9\% en España y 17,0\% en Portugal), y al llegar a la frontera traza la raya de forma intermitente (confusa hasta la firma del Convenio de Límites de Lisboa en 1926 e inconclusa-Olivenza-), durante 140 $\mathrm{km}$ entre las regiones españolas de Extremadura y Andalucía, y las portuguesas de Alentejo y Algarve, con sus afluentes Caya, Ardila y Chanza (Pomarão). Durante $100 \mathrm{~km}$ sirve de límite fronterizo -al presente sustancialmente

10. Acuerdo de Cooperación entre España y Portugal para la constitución del Parque Natural Tajo/Tejo Internacional, firmado en Lisboa el 9 de mayo de 2012 (BOE n. ${ }^{\circ}$ 45, de 18/06/2013). 
modificado por el macro-embalse de Alqueva-, compartiendo aguas en la raya de Huelva-Baixo Alentejo-Algarve (Márquez, 2012).

Al presente, el Guadiana portugués «renace» en Alqueva. Tras diez años de obras y 2.000 millones de euros de inversión declarada, la Barragem d'Alqueva, con sus $4.350 \mathrm{Hm} 3$ de capacidad, $250 \mathrm{~km} 2$ de superficie de agua embalsada (de los que $35 \mathrm{~km} 2$, corresponden a suelo extremeño), $1.160 \mathrm{~km}$ de perímetro de costa dulce interior y $83 \mathrm{~km}$ desde el dique de la presa -de $96 \mathrm{~m}$ de alturahasta la cola-, entró en funcionamiento en febrero de 2002. Alqueva es el mayor lago artificial de la Europa Occidental, más que un lago, un auténtico mar interior que inunda $80 \mathrm{~km} 2$ de 14 términos municipales portugueses (Alandroal, Barrancos, Capelins (Santo António), Juromenha, Monsaraz, Moura, Mourão, Portel, Reguengos de Monsaraz, Santiago Maior, São Bras dos Matos, Serpa, Terena Vidigueira) y de 5 pacenses (Alconchel, Cheles, Olivenza, Táliga y Villanueva del Fresno), unidos en la Asociación Transfronteriza de Municipios de las Tierras del Grande Lago de Alqueva, con enorme potencial turístico para la práctica de actividades náuticas, deportivas y piscícolas (Sánchez Rivero, 2014).

Sin embargo, la gestión náutica de Alqueva ha sido radicalmente distinta. Mientras del lado portugués no hubo más limitaciones que las establecidas en la normativa de navegación, en la «costa extremeña» la Confederación Hidrográfica del Guadiana tiene prohibida la navegación por «seguridad». Y la seguridad se explica, porque al producirse el llenado del embalse las presiones ecologistas consiguieron un informe medioambiental negativo sobre la tala de encinas que, ahora sumergidas junto a postes y tendidos eléctricos, se convierten en un peligro evidente para la navegación, llegando a plantearse el dislate de contratar buzos para realizar ahora la poda submarina...

A mediados de 2013, la Dirección General de Turismo del Gobierno de Extremadura puso en marcha el Parque Temático Natural de Alqueva, con participación de cinco municipios (Olivenza, Alconchel, Cheles, Táliga y Villanueva del Fresno)

El Plan de Competitividad Turística Guadiana Internacional, promovido y gestionado por la Diputación Provincial de Badajoz, tiene como objetivo la creación de productos turísticos (adquisición de una embarcación turística, acondicionamiento de embarcaderos fluviales, controles de navegación, accesos...), ligados a las actividades acuáticas en el Guadiana internacional, represado en el Grande Lago d'Alqueva, y al producto turístico ornitológico «Birding in Guadiana Internacional» (Luna, 2013). 


\section{Andalucía onubense-Baixo Alentejo-Algarve}

Durante $70 \mathrm{~km}$, la frontera del Bajo/Baixo Guadiana es navegable, desde Ayamonte/Vila Real de Santo António (Algarve) hasta Mértola y Pomarão (Baixo Alentejo). Es bien conocido que el río Anas sirvió a lo largo de la Historia de «limes» romano entre la Lusitania y la Bética, durante la dominación musulmana entre el Al-Gharb y el Al-Ándalus, y como vía fluvial de penetración desde la costa onubense al interior, para el transporte de recursos minerales piríticos y agropecuarios, a través de embarcaderos y puertos fluviales interiores (Pomarão -Mértola-y Puerto de la Laja -El Granado-). A partir de Pomarão se inicia el último tramo del Bajo Guadiana internacional hasta la desembocadura. En zona tan hostil al poblamiento con redes camineras arcaicas, el Guadiana se convirtió en el único eje fluvial de comunicaciones entre la costa y el interior, pero su cauce encajado y la inexistencia de puentes impidió las relaciones directas entre los núcleos rayanos de Sanlúcar de Guadiana-Alcoutim, El GranadoMértola y Paymogo-Serpa. El aislamiento histórico y el rodeo de $180 \mathrm{~km}$ entre El Granado y Mértola se rompió en 2009 con la construcción del puente sobre el río Chanza, al igual que entre Paymogo y Serpa con el puente sobre el Chanza (Jurado, 2014a), inaugurado en 2012 por la profesora Josefina Cruz Villalón.

En la raya onubense se solapan los espacios naturales protegidos de la Red RENPA de la Junta de Andalucía y de la Red Natura 2000 de la Unión Europea. En la franja intermedia del Andévalo Occidental se registran Lugares de Interés Comunitario (LIC) y Zonas de Especial Conservación (ZEC), que han conseguido frenar las presiones urbanísticas de la orilla izquierda del Guadiana y del Chanza.

\section{Parque Natural de Vale do Guadiana}

Con superficie de 70.000 hectáreas se extiende desde Pulo de Lobo a la Ribera do Vascão, entre las villas alentejanas de Mértola y Serpa, en el contacto entre el Baixo Alentejo SE y el NE algarvio. Integra tres unidades paisajísticas bien diferenciadas: valles encajados del Guadiana y sus afluentes; crestones cuarcíticos de las sierras de Alcaria y São Barão, y la penillanura adehesada dominante. El Guadiana, represado en Alqueva y más tarde en Pedrogão, recorre después libremente el curso hasta la desembocadura. El elemento geológico más destacable del Parque es Pulo do Lobo (Salto del Lobo) por el que se precipitan las aguas del Guadiana con caída de 20 metros por una garganta rocosa.

La oferta turística de la provincia de Huelva se centra en el modelo de sol y playa del litoral onubense (Parque Nacional de Doñana, Isla Antilla e Isla Canela) y algarvio (Castro Marim, Vila Real de Santo António y Monte Gordo), en detrimento del Bajo Guadiana fluvial (Sanlúcar de Guadiana) y Baixo Guadiana (Alcoutim y Mértola), que aún no puede catalogarse como 
destino turístico de interior, pese al enorme potencial de su navegabilidad desde Ayamonte hasta Mértola-Pomarão, contemplada en los proyectos POCTEP de Cooperación turística transfronteriza (2007-2013).

Los potenciales turísticos del Bajo/Baixo Guadiana, aún inexplotados, demandan la creación del Parque Natural Transfronterizo del Bajo Guadiana, para una administración ambiental conjunta que posibilite el aprovechamiento de los recursos naturales y culturales. La mejora sustancial de la red viaria, la construcción de los puentes internacionales y hasta la Tirolina Transfronteriza España-Portugal de David Jarman ${ }^{11}$, con 7.500 usuarios en el primer año de explotación (2014), invitan a ello. Iniciativa empresarial ésta de creación de producto turístico innovado, que ha debido superar los enmarañados trámites administrativos transfronterizos (tres años y medio para la obtención de la licencia de explotación), pero que está sirviendo de punta de lanza para la regeneración económica de Alcoutim y Sanlúcar de Guadiana, pequeños municipios rurales en declive. Mértola, en cambio, ha despegado gracias al Campo Arqueológico.

El proyecto «Territorio y Navegabilidad en el Bajo Guadiana» (ANDALBAGUA) se insertó en el Programa Operativo de Cooperación Transfronteriza España-Portugal (POCTEP 2007-2013), dentro del eje prioritario «Accesibilidad y Ordenación Territorial de la Eurorregión AndalucíaAlentejo-Algarve (AAA) ${ }^{12}$, analizado por (Márquez; Gordo; Jurado, 2012).

\section{PRODUCTOS TURÍSTICOS: CRUCEROS FLUVIALES}

De la variada oferta de productos turísticos vinculados al agua nos decantamos en esta comunicación, en homenaje al querido profesor y buen amigo Alfredo Morales, por los cruceros fluviales de interior, una tipología en auge, de gran atractivo y enorme potencialidad turística de futuro, al navegar por los Parques Naturales transfronterizos de gran personalidad paisajística, avenados por los ríos Duero, Tajo y Guadiana.

\section{Lago de Sanabria}

Desde el 17 de junio de 2011 la empresa Europarques oferta un crucero ambiental por el Parque Natural del Lago de Sanabria en el Barco Helios Sanabria,

11. LÍMITE ZERO. Tirolina Transfronteriza España-Portugal, con recorrido de $720 \mathrm{~m}$ entre Sanlúcar de Guadiana y Alcoutim, y descenso a $70 \mathrm{~km} /$ hora sobre el cauce del Guadiana. Experiencia turística vivida, que recomiendo, www.limitezero.com

12. POCTEP 2007-2013 1. . Convocatoria. Proyecto ANDALBAGUA: Territorio y navegabilidad en el Bajo Guadiana. Secretaría General de Acción Exterior, Junta de Andalucía. Financiación FEDER en miles de euros: 3.071,6. POCTEP 2007-2013 2. ${ }^{\text {a }}$, Convocatoria. Proyecto GUADIANA: Guadiana: uma via navegável. Algarve y Andalucía. Instituto Portuário e dos Transportes Marítimos. Delegação do Sul. Financiación FEDER en miles de euros: 1.350. 


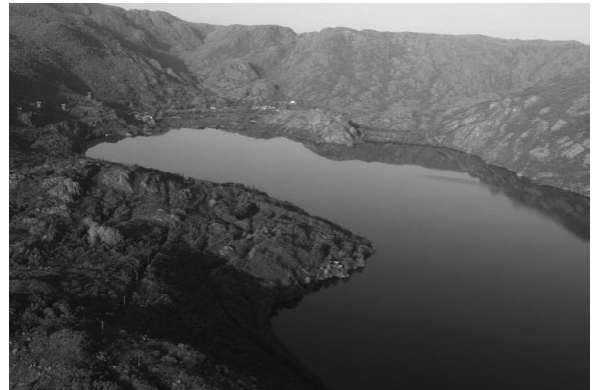

P. N. del Lago de Sanabria. (Puebla de Sanabria).

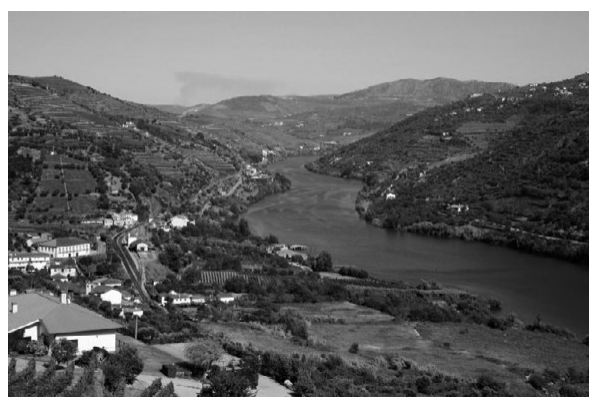

Alto Douro Vinhateiro. Patrimonio Mundial.

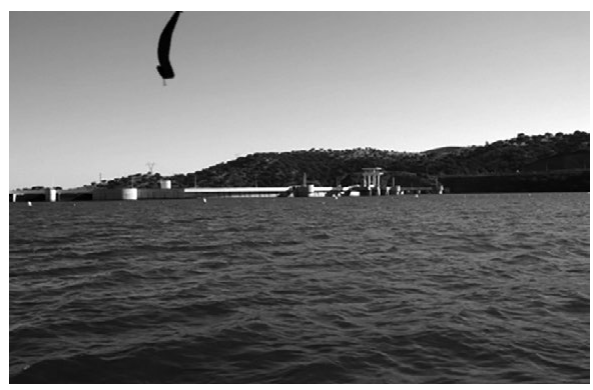

Parque Temático Natural de Alqueva.

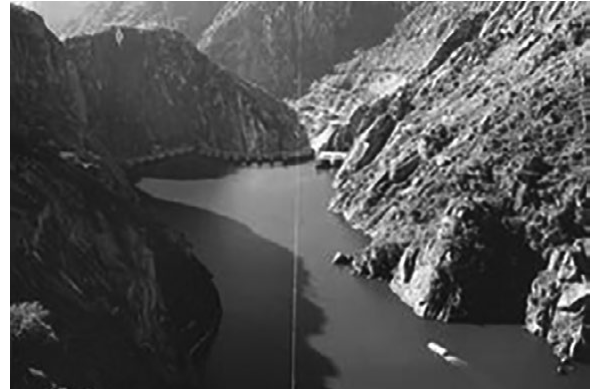

P. N. Arribes del Duero. (Aldeadávila de la Ribera).

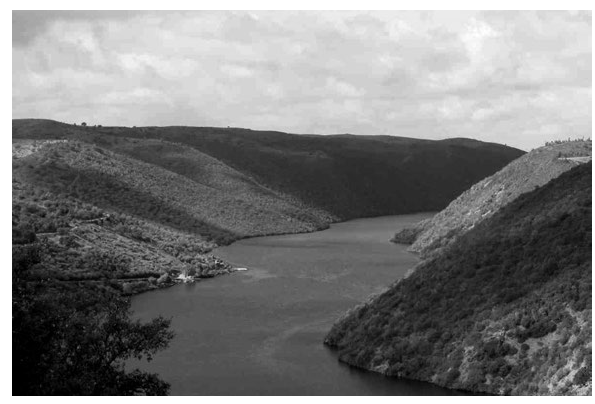

P. N. Tajo Internacional.

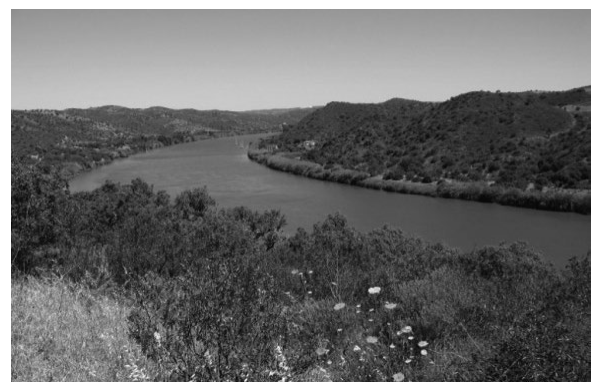

Parque Natural de Vale do Guadiana.

Figura. 1. Paisajes patrimoniales del agua en la Raya ibérica

primer catamarán de propulsión eólico-solar, con 4 aerogeneradores y 20 paneles solares de silicio verde semi-trasparente para mayor mimetización ambiental, que mueven los dos motores eléctricos del barco de $19 \mathrm{~m}$ de eslora y $6 \mathrm{~m}$ de manga con capacidad para 100 plazas. Está dotado de la última tecnología punta con impacto ambiental nulo en emisiones de residuos y decibelios. El punto de embarque se realiza en la Custa Lago, la playa principal del Lago de Sanabria, al 
que se accede desde la Autovía de las Rías Bajas (A-52) Benavente-Vigo, salida 79 hacia la carretera provincial ZA-104 con $12 \mathrm{~km}$ de recorrido hasta el lago. Realiza recorridos turísticos y didácticos de 90 minutos entre Custa Lago y la playa de Moras y Bouzas con retorno al punto de partida. Como recursos adicionales, ofrece un Aula Tecnológica de Interpretación del glaciarismo del Lago de Sanabria y cámaras robotizadas para la exploración subacuática. Como actividades complementarias ofrece la visita al pueblo de Ribadelago Viejo (arruinado por la rotura de la presa de Vega de Tera el 9 de enero de 1959) y degustación de sidra sanabresa. Dispone del Centro de Interpretación de las Casas del Parque. https:/www.europarques.com / cpsanabria@patrimonionatural.org

\section{Las Arribes del Duero}

En el cañón del río Duero se localizan las principales ofertas turísticas de cruceros fluviales, entre las láminas de aguas tranquilas de los embalses de Miranda do Douro, Bemposta, Aldeadávila y Saucelle. Asimismo, existen otras ofertas náuticas en los embalses de Almendra -Tormes- (Cibanal, Villar del Buey) por la empresa «Sayago Natural»; de Villalcampo, por la empresa «Salto 2002, Turismo Activo», y en el salto de Valparaiso.

Embalse de Miranda do Douro

El Navío-Aula Ecológica «Escua» es un catamarán propiedad de la empresa Europarques Hispano-Lusos S.R.L., con capacidad para 120 plazas, movido por motores ecológicos insonorizados de doble propulsión independiente que se ajustan a las exigencias medioambientales del recorrido, cubierta interior, acristalada y climatizada, tres cubiertas exteriores a proa y a popa, con capacidad para todo el pasaje, dos cuartos de baño, visión por infrarrojos y últimas tecnologías de salvamento y navegación, dos cuartos de baño y balsas auto-hinchables. El punto de embarque se encuentra en la margen derecha del Duero (Parque Natural Douro Internacional), cerca de la presa, en la Estación Biológica Internacional (E.B.I.) luso-española, donde se ubica el Centro Ambiental Hispano-Luso Lda., en la raya de Zamora/Miranda do Douro (Portugal), desde donde realiza un recorrido de 1 a 3 horas, entre Miranda do Douro y Valle del Águila. Este barcolaboratorio, con gran número de proyectos ambientales de cooperación transfronteriza, ofrece un crucero ambiental por el Parque Natural, con explicación geográfica del cañón de paredes graníticas verticales de 200 m, de las terrazas abancaladas con cultivos tradicionales, de las rutas de los contrabandistas y de la Calzada Mirandesa. Como actividades complementarias, incorpora recorridos etnográficos, gastronómicos y culturales, degustación de vinho do Porto, exhibición interactiva con fauna del Programa de Recuperación y Cría en Cautividad (Devesa das Rapinhas) y visita a Miranda do Douro, villa fronteriza patrimonial, 
con equipamiento hotelero, comercio para turismo de compras y buena cocina. Parte de los beneficios de la explotación se destina a proyectos de investigación y conservación de los recursos naturales del Parque. https://www.europarques. com / info@europarques.com

\section{Embalses de Bemposta y Picote}

El Barco Arribas es un pequeño catamarán de 12 plazas propulsado por motor diésel, que ofrece un crucero ambiental por el Parque Natural do Douro Internacional, a la altura del municipio zamorano de Fermoselle, con recorrido de 120 minutos entre las presas portuguesas de Bemposta y Picote, permitiendo la observación de naturaleza, fauna y vegetación mediterránea del microclima de Las Arribes. https://www.corazondelasarribes.com / turismo@corazondelasarribes.com

\section{Embalse de Aldeadávila de la Ribera}

El Corazón de Arribes es un catamarán propiedad de la empresa Europarques, propulsado por motor diésel con 100 plazas de capacidad, cerramiento abovedado elevable de cristal panorámico, calefacción y aire acondicionado, aseo y terraza a popa, megafonía y sistemas de seguridad. El punto de embarque lo tiene en la Playa del Rostro-Corporario, paraje a $5 \mathrm{~km}$ de Aldeadávila de la Ribera (Salamanca), a $320 \mathrm{~m}$ de altitud. Se accede desde la Autovía A-62 (Salamanca-Ciudad Rodrigo), tomando la salida de Fuentes de San Esteban a Vitigudino (SA-315) y después la (SA-314) con pronunciado descenso en automóvil hasta el aparcamiento de la Playa del Rostro-Corporario. El crucero ambiental ofrece rutas guiadas didáctico-ambientales en un viaje de 90 minutos y $22 \mathrm{~km}$ de recorrido total, ida y vuelta, desde el embarcadero hasta la presa de Aldeadávila de la Ribera, con una solvente interpretación geográfica sobre Las Arribes, el cañón, los cortados verticales de granito (que aquí superan los 400 $\mathrm{m}$ sobre la presa y cachones, más otros $100 \mathrm{~m}$ de profundidad del embalse) y la flora y fauna (águila real y perdicera, cigüeña negra, alimoches, búho real...), que anidan en los cantiles. Como actividades complementarias se ofrecen baños en la playa fluvial, piragüismo y visita cultural al Museo Majada del Rostro. https://www.corazondelasarribes.com / corarondearribes@gmail.com

\section{Embalse de Saucelle}

La Barca de Vilvestre, propiedad de la Sociedad Transfronteriza Congida-La Barca, es un barco cerrado de 55 plazas, propulsado por motorización diésel, con calefacción, aire acondicionado, aseo, terraza, cafetería, megafonía y sistemas de seguridad náutica. El punto de acceso es el embarcadero de La Barca, a $3 \mathrm{~km}$ del municipio de Vilvestre (Salamanca), al que se accede por la carretera (CL-517), de Salamanca a Vitigudino y por la (SA-320) de Vitigudino a 
Vilvestre-La Barca. Ofrece un crucero ambiental por el Duero y Águeda, de $20 \mathrm{~km}$ de recorrido aguas arriba de la presa de Saucelle, entre la Playa de La Congida y La Code (Mieza), con retorno, compartiendo el paisaje de los dos Parques Naturales, de las Arribes y del Douro Internacional.

https://www.losarribesdelduero.com

Por el muelle antiguo de Vega Terrón, construido en el término de La Fregeneda, donde el Águeda desemboca en el Duero para convertirse en Douro portugués hasta Porto, circulaban a mediados del xIX productos exportados e importados (agro-ganaderos, textiles, madera, hierro) desde Castilla y Extremadura a Portugal. Tras su clausura y abandono, resurgió en los años 80 y 90 del siglo xx con el proyecto de navegabilidad del Duero hasta Porto, construyéndose el nuevo muelle (Cabo, 1989).

Del lado portugués, destaca la oferta de navegabilidad del Duero, mediante esclusas, en las presas de Carrapatelo, Régua, Valeira y Pocinho, con embarque en los muelles del puerto fluvial de Vega Terrón (La Fregeneda), desde donde se puede navegar el Duero hasta su desembocadura en Porto, y de Barca d'Alva (Figueira de Castelo Rodrigo), con paquetes turísticos muy atractivos que permiten la visión del Alto Douro Vinhateiro (Patrimonio Mundial), con sus pronunciadas laderas abancaladas (socalcos) y visitas a las quintas bodegueras del Vinho do Porto (Hortelano, 2014a).

$\mathrm{http}: / /$ turismofluvial.com/turismo-fluvial-portugal.html

$\mathrm{http}: / /$ vivelasarribes.es/puertos-y-playas/muelle-de-vega-terron.html

$\mathrm{http}: / /$ vivelasarribes.es/puertos-y-playas.html

\section{Tajo/Tejo Internacional}

El Balcón del Tajo, propiedad de la Diputación Provincial de Cáceres, fue construido en los astilleros gallegos de Ulloa por 507.895 euros, cofinanciados entre la Unión Europea (75\%) y la Diputación Provincial de Cáceres-Junta de Extremadura (25\%) con puesta en servicio en marzo de 2011, mediante cesión de explotación al operador turístico privado OPTITUR, Productos de Factor Ocio. Es un barco cerrado, propulsado por motores diésel y eléctrico totalmente silencioso, que navega lento a velocidad de $12 \mathrm{~km} /$ hora al atravesar las áreas de nidificación, con cubierta superior, de $16 \mathrm{~m}$ de eslora y $5,5 \mathrm{~m}$ de manga, capacidad para 80 viajeros, calefacción, aire acondicionado, aseo, cafetería, megafonía, sistemas de seguridad y visión subacuática.

Para las tres rutas náuticas ofertadas: (Cedillo-Herrera de Alcántara; Herrera de Alcántara-Santiago de Alcántara, y Cedillo-Lentiscais-Malpica do Tejo) existen tres embarcaderos en los municipios de Cedillo, Herrera de Alcántara y Santiago de Alcántara (cuyo coste, según Diputación, fue de 311.000 euros), a los que se accede por la N-521 (Cáceres-Valencia de Alcántara), y de ésta por 
la EX-374 y EX-375 a los tres municipios, o bien de Cáceres a Alcántara por la EX-207 y desde la villa de Alcántara a Membrío (EX-117) y de allí por la CC-126 a Santiago de Alcántara y restantes puntos de embarque.

El paso por el dique de la presa de Cedillo es potestativo de Iberdrola, que lo concede los fines de semana, mediante un acuerdo entre la empresa hidroeléctrica, el Ayuntamiento y la Junta de Extremadura, lo que supone la privatización del acceso público de una frontera internacional. El presunto proyecto de puente internacional sobre el río Sever (3,53 millones de $€$ para el puente y 5 millones para los accesos) fue aparcado definitivamente por el presidente de la Diputación Provincial de Cáceres en el Pleno de 18 de diciembre de 2013, al no considerarlo una inversión prioritaria («no tiene sentido un puente en mitad de la nada»), pese a disponer de financiación comunitaria a través del Programa Operativo de Cooperación Transfronteriza España-Portugal (POCTEP). Un problema de incomunicación internacional candente, con años de lucha, para los 600 habitantes de Cedillo que lo sufren a diario de lunes a viernes, al igual que para los vecinos portugueses de Montalvão, Nisa, Vila Velha de Rodão y Malpica. De haber puente, los $14 \mathrm{~km}$ de distancia entre Cedillo y Montalvão, que se recorrerían en 15 minutos, suponen hoy $140 \mathrm{~km}$ de rodeo por Valencia de Alcántara y dos horas de duración. Cedillo, queda así aislado en fondo de saco por intereses privados y públicos.

Como Aula Ecológica, dotada de un guía de la naturaleza que explica todos los detalles de flora y fauna, el crucero ambiental que funciona todo el año ofrece la posibilidad de tres recorridos (de medio día -2 horas-; de día completo -7 horas-, y de fin de semana - de viernes tarde a domingo-). Combina la navegación con ofertas de rutas turísticas (megalitismo, senderismo, visita a secadero de jamones, turismo de compras en Castelo Branco...). Múltiples son las motivaciones turísticas de los viajeros atraídos por el desconocido y singular paisaje atlántico-mediterráneo transfronterizo, desde ornitólogos, para avistamiento de las 181 especies de aves y las 47 variedades de mamíferos y fauna fluvial -nutrias, galápago europeo, siluros, carpas, bogas, percas y cangrejos de río- a grupos de estudiantes, retornados veraniegos de julio y agosto, familias con niños, amantes de la naturaleza, senderistas, clubes senior...). Uno de los puntos más atractivos del Parque Natural Tajo/Tejo Internacional es el escalonamiento de nidos de buitres, cigüeñas negras y alimoches, tres especies sobre un crestón pizarroso compartido. Las rapaces, lejos de inquietarse, como pregonan los ecologistas, se muestran dispuestas a posar para las cámaras. Para la interpretación del Parque Natural existe un Centro de Visitantes, ubicado en una casa solariega del siglo XVII en Alcántara, otro Centro de Visitantes «El Casón», en el Museo Etnográfico de Cedillo, y el Centro de Interpretación del Parque Natural «El Péndere», ubicado en la Ermita del Péndere (XIII) en Santiago de Alcántara. www.turismotajointernacional.com 
Durante el primer año de funcionamiento el número de pasajeros ascendió a 31.108 , llegando a 45.000 a los 16 meses, creando 7 puestos de trabajo directos y 50 indirectos y generando ingresos turísticos en el territorio por un montante de 1.085.630 € (Sánchez Rivero, 2014). En sus cuatro años de existencia, a 6 de marzo de 2015, han pasado por el barco más de cien mil visitantes (100.539), con un movimiento generado en la zona de 4 a 5 millones de euros, según Rafael Pintado, responsable de Productos de Factor Ocio, la empresa que dirige el proyecto de alto valor ecológico. Todo un revulsivo para el desarrollo económico de la Raya cacereña.

www.barcodeltajo.com / reservas@barcodeltajo.com

Los visitantes que llegan al Tajo Internacional, fundamentalmente en primavera y verano, son extremeños en un $74 \%$, mientras el $24 \%$ restante reparte su procedencia entre nacionales (madrileños, castellano-leoneses andaluces, catalanes y vascos) y extranjeros ( $2 \%$ ) portugueses, franceses y alemanes, motivados por ornitología, naturaleza, gastronomía, caza, pesca, y cultura, con una experiencia tan satisfactoria que invita a repetirla (AA, VV., 2011). La media de gasto por visitante se sitúa entre los 45 y 50 euros, de los que 15 es el precio mínimo del billete del barco. La repercusión en la actividad alojativa (casas rurales) y restauradora es manifiesta, como se constata en el mini-municipio cacereño de Herrera de Alcántara (275 habitantes), cuyos restaurantes han pasado de servir 20 comidas a 150 diarias, desde que el barco entró en funcionamiento. Por su parte el núcleo de Castelo Branco (cabecera distrital de la Beira Interior Sul con 43.000 habitantes), que no recibe flujos turísticos rayanos por carretera, al no haberse conectado aún los $70 \mathrm{~km}$ entre las autovías A-23 portuguesa y la EX-A1 extremeña $(57 \mathrm{~km}$ de la IC13 de Castelo Branco a Monfortinho y 12 km de la EX-108, de Monfortinho a Moraleja), gracias al barco está recibiendo 12.000 turistas anuales, con notable repercusión en comidas y compras.

Con buen criterio, la Dirección General de Turismo del Gobierno de Extremadura está ensamblando al turismo de naturaleza las ofertas complementarias (gastronómica, cultural y de compras). Una experiencia náutica-fluvial de turismo de crucero, única por atractivo, potencial y desconocimiento del territorio, que se significa como uno de los proyectos punteros del Programa de Cooperación Transfronteriza entre España y Portugal POCTEP (2007-2013), tutelado por la Diputación Provincial de Cáceres para fomentar el desarrollo económico del Parque Natural compartido entre las comarcas cacereñas fronterizas de San Pedro-Los Baldíos y Tierra de Alcántara. 


\section{Guadiana Internacional}

Guadiana luso-extremeño: Grande Lago d'Alqueva

En la Barragem d'Alqueva las ofertas de turismo náutico (cruceros, veleros, alquiler de botes, casas flotantes) y los passeios de barco constituyen una de las demandas turísticas de mayor calado. A diario, varias empresas ofrecen rutas náuticas de una o varias horas en barcos a motor de 120 personas o veleros, desde los embarcaderos de la Marina da Amieira, Cais da Barragem y Cais de Monsaraz, con paradas en las aldeias ribeirinhas.

www.roteirodoalqueva.com

Amieira Marina / Gescruzeiros, ubicada en Amieira (Portel), integra una variada oferta de productos náuticos: alquiler de barcos-casa, alquiler de barcos por un día, cruceros de 6 a 120 personas en los barcos Guadiana y Alcarreche e Degebe, en recorridos de 30 a 180 minutos, alquiler de amarraderos para embarcaciones particulares con servicios técnicos de mantenimiento y reparación, cursos de navegación y de vela.

Livre de Amarras, empresa ubicada en Póvoa de São Miguel, (Moura), dentro del complejo náutico de Amieira Marina, ofrece servicios turísticos orientados a la vela.

Alquevaline / Alquevabass, operador marítimo turístico ubicado en Moura (Beja), ofrece paseos especializados en barcos con actividades variadas, cruceros, alquiler de barcos, guías de pesca.

Capitán Tiago, empresa ubicada en Monte dos Poços Novos -Telheiro(Reguengos de Monsaraz), opera desde el Cais (embarcadero) de Monsaraz con la lancha Alqueva Cruzeiro para 12 usuarios y recorrido hasta las localidades de Mourão, Luz, Estrela y Alqueva, además de actividades de vela, ski acuático, rutas en kayak...

Barcos Casa, hace lo propio para pequeños grupos de hasta 12 personas.

Resulta inconcebible que, mientras del lado portugués el desarrollo náutico en Alqueva se desarrolla sin problemas, del extremeño todos sean problemas para navegar desde los tres embarcaderos de Villarreal (Olivenza), Cheles y Villanueva del Fresno. La Confederación Hidrográfica del Guadiana mantiene sus exigencias de no permitir la navegación por las aguas españolas, ni siquiera de embarcaciones de fondo plano sin motor. Está pendiente de realizar la carta náutica, preceptiva para navegar, y que contempla el proyecto Adla. Los tres embarcaderos cuentan con una señalización de boyas en un tramo de un $\mathrm{km}$ aguas arriba y otro km abajo, hasta cuyo límite está permitido el uso de canoas y 
embarcaciones de fondo plano. Fuera de esos límites, además del riesgo de accidente, está garantizada la multa por el Seprona de la Guardia Civil. Contradicción transfronteriza que tendrá que resolver la Comisión Hispano-Lusa.

\section{Bajo/Baixo Guadiana onubense-algarvio}

Desde la desembocadura en Ayamonte-Vila Real de Santo António hasta la confluencia con el Chanza, el Bajo Guadiana internacional es navegable a lo largo de $50 \mathrm{~km}$ hasta Mértola y Pomarão, puertos fluviales históricos desde época romana con patrimonio histórico secular, lo que ofrece un enorme potencial de futuro por la relación entre navegación marítima en el litoral onubense-algarvio, de alta concentración turística nacional e internacional, y navegación fluvial de interior, con embarcaderos fluviales paralelos de Sanlúcar de Guadiana (Huelva) y Alcoutim (Algarve), conectados hoy por lanchas motoras, y los pequeños embarcaderos portugueses de Foz de Odeleite y Guerreiros do Rio (Jurado y Pazos, 2014).

La atracción del río Guadiana se constata en la profusión de embarcaciones (veleros) que, procedentes del litoral onubense-algarvio, remontan el cauce a favor de las mareas hasta los puertos fluviales de Sanlúcar de Guadiana / Alcoutim, (con mutaciones completas de fisonomía y funcionalidad), antiguo Puerto de la Laja (en el municipio del Granado) Mértola y Pomarão. El Bajo/ Baixo Guadiana es uno de los últimos paraísos por descubrir, con naturaleza intacta, testimonios culturales bimilenarios y atractivos turísticos que, naturalmente, son apreciados y explotados por los extranjeros con reminiscencias neohippies, procedentes de la costa del Algarve, que fondean sus barcos en medio del cauce para vivir en ellos y en algunas pequeñas construcciones de madera en la orilla portuguesa.

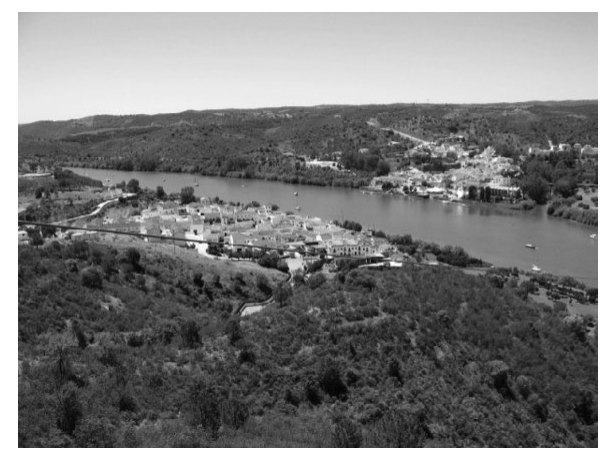

Sanlúcar de Guadiana / Alcoutim (Algarve).

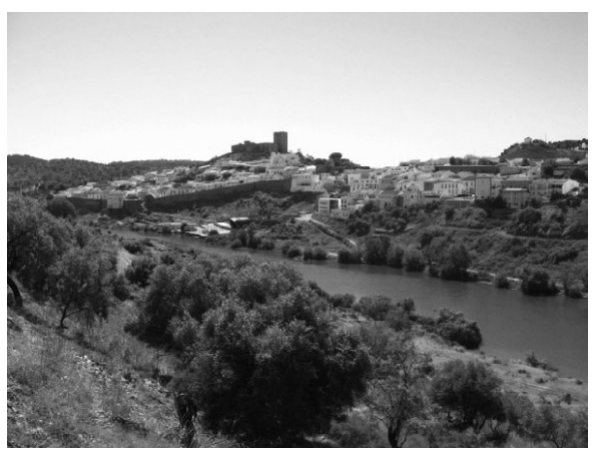

Mértola (Baixo Alentejo).

Figura 2. Villas rayanas del Bajo/Baixo Guadiana 


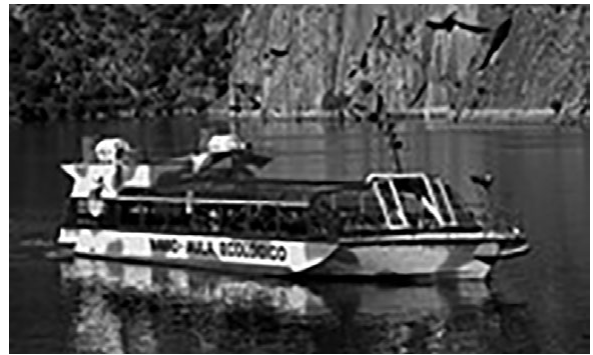

Helios-Sanabria (Puebla de Sanabria).

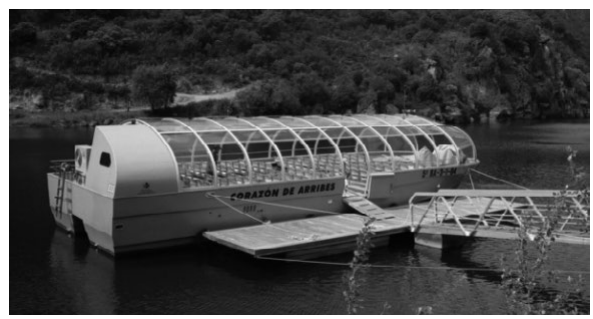

Corazón de Las Arribes. Aldeadávila de la Ribera.

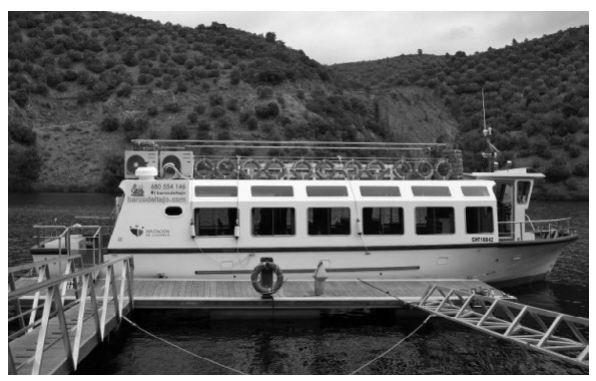

Balcón del Tajo (Cedillo).

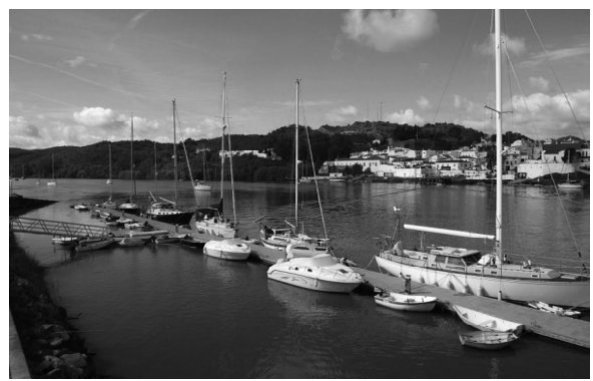

Embarcadero de Sanlúcar de Guadiana (Huelva).

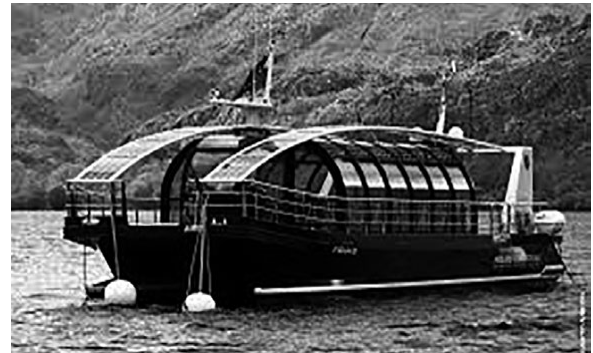

Navío Aula Ecológico E.B.I. (Miranda do Douro).

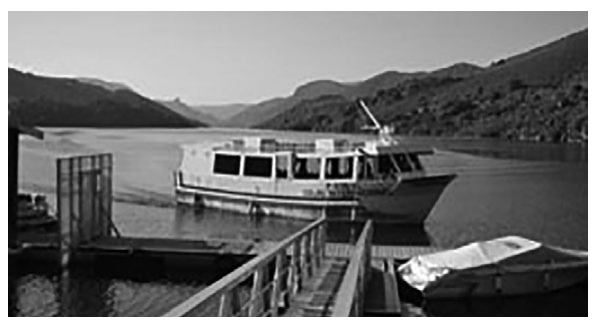

Barca de Vilvestre (Salamanca).

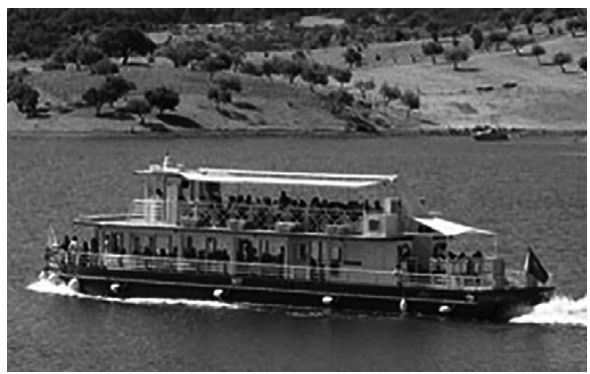

Barco Guadiana. Amieira Marina.

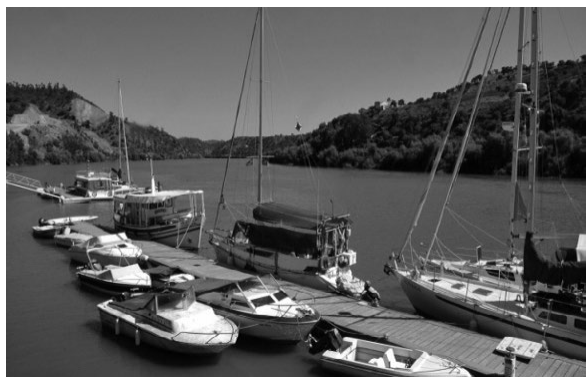

Embarcadero de Pomarão.

Figura. 3. Cruceros fluviales por la Raya ibérica. 
Tabla 1

Parques Naturales y cruceros fluviales en la Raya ibérica

\begin{tabular}{|c|c|c|}
\hline $\begin{array}{l}\text { TERRITORIOS } \\
\text { RAYANOS }\end{array}$ & $\begin{array}{l}\text { RECURSOS } \\
\text { NATURALES }\end{array}$ & $\begin{array}{l}\text { PRODUCTOS } \\
\text { TURÍSTICOS }\end{array}$ \\
\hline Regiones & Parques Naturales & Cruceros fluviales \\
\hline \multirow[t]{3}{*}{$\begin{array}{l}\text { Castilla y León / } \\
\text { Trás-os-Montes / } \\
\text { Beira Interior } \\
\text { Norte }\end{array}$} & $\begin{array}{l}\text { Parque Natural del Lago de } \\
\text { Sanabria } \\
\text { Parque Natural Arribes del Duero }\end{array}$ & $\begin{array}{l}\text { Barco Helios Sanabria (Lago de } \\
\text { Sanabria. Galende. Zamora) } \\
\text { Barco Arribas. Naturisnor-Turismo } \\
\text { de Natureza do Nordeste (Embalse } \\
\text { de Bemposta. Fermoselle. Zamora) } \\
\text { Barco Corazón de Las Arribes } \\
\text { (Embalse de Aldeadávila de la } \\
\text { Ribera. Salamanca) } \\
\text { Barca de Vilvestre. Sociedad } \\
\text { Transfronteriza Congida/La Barca } \\
\text { (Embalse de Saucelle. Vilvestre, } \\
\text { Salamanca / Freixo de Espada à } \\
\text { Cinta.) }\end{array}$ \\
\hline & $\begin{array}{l}\text { Parque Natural Douro } \\
\text { Internacional }\end{array}$ & $\begin{array}{l}\text { Crucero Ambiental de Arribes del } \\
\text { Duero (Embalse de Miranda do } \\
\text { Douro) }\end{array}$ \\
\hline & Cruceros fluviales hasta Porto & $\begin{array}{l}\text { Crucero del Souro Vega Terrón (La } \\
\text { Fregeneda), Salamanca-Porto } \\
\text { Barca d'Alva. Figueira de Castelo } \\
\text { Rodrigo. }\end{array}$ \\
\hline $\begin{array}{l}\text { Extremadura / } \\
\text { Alentejo / } \\
\text { Região Centro }\end{array}$ & $\begin{array}{l}\text { Parque Natural Tajo/Tejo } \\
\text { Internacional }\end{array}$ & Crucero fluvial «Balcón del Tajo». \\
\hline $\begin{array}{l}\text { Guadiana } \\
\text { Internacional: } \\
\text { Barragem } \\
\text { d'Alqueva }\end{array}$ & $\begin{array}{l}\text { Parque Temático Natural de } \\
\text { Alqueva. } \\
\text { Grande Lago d'Alqueva }\end{array}$ & $\begin{array}{l}\text { Amieira Marina / Gescruzeiros. } \\
\text { Livre de Amarras. } \\
\text { Alquevaline / Alquevabass. } \\
\text { Capitán Tiago. } \\
\text { Barcos Casa. }\end{array}$ \\
\hline $\begin{array}{l}\text { Andalucía } \\
\text { onubense / } \\
\text { Baixo Alentejo / } \\
\text { Algarve }\end{array}$ & $\begin{array}{l}\text { Bajo/Baixo Guadiana } \\
\text { Internacional } \\
\text { Parque Natural de Vale do } \\
\text { Guadiana }\end{array}$ & $\begin{array}{l}\text { Transporte Fluvial del Guadiana. } \\
\text { Ayamonte. } \\
\text { Huelva Holidays. Ayamonte. } \\
\text { Guadiana XtremmE. } \\
\text { Sanlúcar de Guadiana. } \\
\text { Fun River. Alcoutim. }\end{array}$ \\
\hline
\end{tabular}

Elaboración propia.

Desde Vila Real de Santo António y Ayamonte existen ofertas de excursiones en barco, que remontan el río hasta Sanlúcar de Guadiana y Mértola-Pomarão, con duración de un día desde las 10:00 de la mañana hasta las 17:00, incluyendo comida, tapeo, gambas y música, gestionadas por las empresas: Transporte 
Fluvial del Guadiana (Ayamonte) www.rioguadiana.net; Huelva Holidays (Ayamonte) www.huelvaholidays.es; Fun River, Empresa de Ocio Activo de Alcoutim (Portugal) www.fun-river.com, y Guadiana XtremmE. (Sanlúcar de Guadiana) www.guadianaextremme.com

\section{CONCLUSIONES}

Numerosos en cantidad y calidad son los recursos patrimoniales de la Raya ibérica, pero muy escasos los productos turístico-culturales derivados de su manufacturación, promoción y comercialización, hasta el extremo de que debamos hablar más de potenciales con atractivos y rentabilidad expectante que de productos turísticos, propiamente dichos, ofertados en el mercado. Para la definición de los productos es necesario aplicar el factor de ponderación, añadiendo a la naturaleza y singularidad del recurso el poder de atracción que ejerce la demanda sobre ellos (Sánchez Martín, 2014).

La hipótesis de partida de que cuanto mayor sea el valor del bien ofertado (recurso-producto), mayor será la atracción de visitantes que genere, relaciona el valor del bien ofertado con la demanda que lo desea y sus motivaciones. Las preferencias de la demanda son esenciales como índice de valoración, porque facilitan el interés turístico actual y el potencial. El nivel de uso, en la mayor parte de los casos, se encuentra por debajo de su potencial real, debido a causas externas al propio recurso: accesibilidad, falta de conocimiento de su existencia, y ausencia de infraestructuras básicas. Una de las aportaciones investigadoras del Proyecto TURFRONT (2012-2014) ha sido la elaboración por el profesor

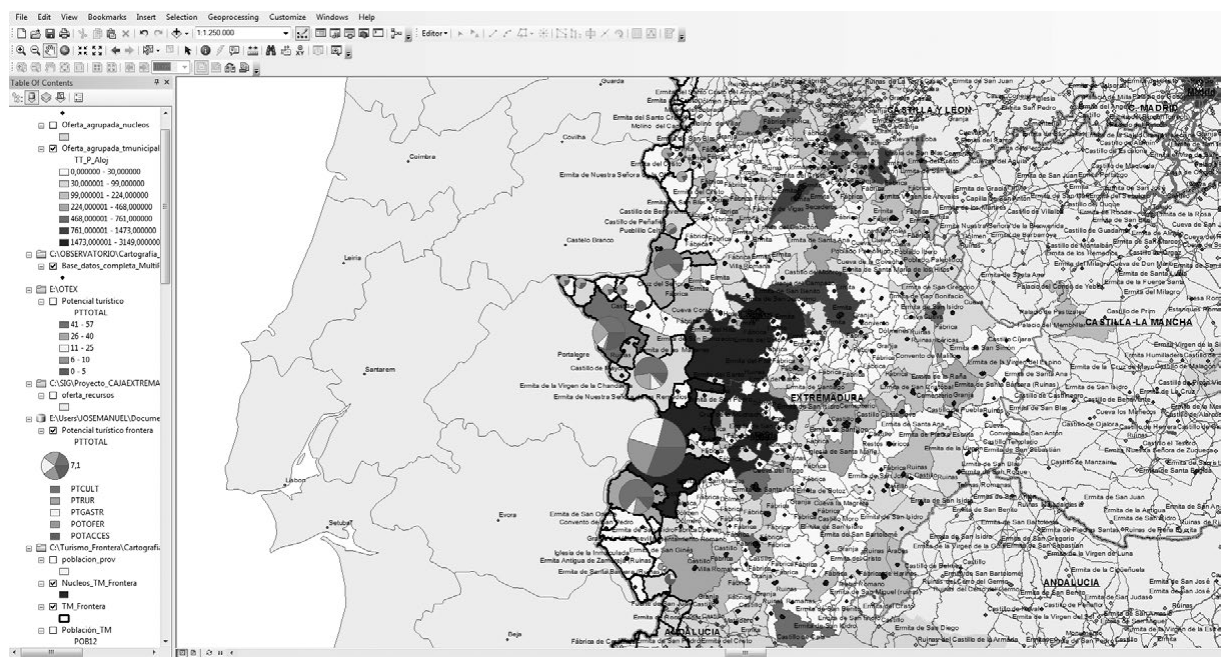

Figura 4. Mapa de Potenciales turísticos de la Raya de Extremadura. Autor: José Manuel Sánchez Martín. Proyecto TURFRON (2012-2014) 
José Manuel Sánchez Martín del mapa de potenciales turísticos de la Raya de Extremadura, que se contiene en la Figura 4.

La perfecta simbiosis en la Raya ibérica entre paisajes del agua, protegidos con declaración patrimonial de Parques Naturales, y turismo fluvial de cruceros náuticos, constituye un atractivo individual indiscutible con enorme potencial de futuro. Lo presumen las crecientes demandas de visitantes y turistas, motivadas por la calidad ambiental de los paisajes diferenciados, por el propio atractivo náutico de interior y por la multitud de ofertas complementarias en segmentos turísticos de naturaleza, cultura, gastronomía, ornitología, caza y pesca, deportes náuticos, senderismo...

En una docena de años, las mutaciones paisajísticas en el ámbito de la EUROACE (Eurorregión Alentejo-Centro-Extremadura) han sido extraordinarias por efecto de Alqueva. Los paisajes adehesados y los montados alentejanos seculares han desaparecido bajo la inmensa lámina de agua del Guadiana represado, que ofrece un horizonte lineal, uniforme e infinito. Las mutaciones de los usos del suelo suponen cambios drásticos de formas de vida y aprovechamientos para poblaciones tradicionales de medios rurales en declive, envejecidas y de baja formación y cualificación. El tránsito del sector primario agro-ganadero al sector terciario de servicios turísticos náuticos se antoja un salto en el trapecio sin red con graves problemas de reciclaje.

... El «Turismo de la Raya Ibérica» es el reto estratégico de la Cooperación Transfronteriza Luso-Española de Segunda Generación (2014-2020).

BiBLIOGRAFÍA

AA. VV. (1989): Los paisajes del agua. Libro jubilar dedicado al profesor Antonio López Gómez. Universitat de Valencia, Universidad de Alicante, Valencia.

AA. VV. (2011): Creación de Productos Turísticos en el Parque Natural Tajo Internacional. Dirección General de Turismo del Gobierno de Extremadura, Mérida.

Azevedo, J. (Ed.) (1998): Entre Duas Margens. Douro Internacional. Tipografía Guerra, Mirandela.

Bucho, D. (2010): Património, Animação e Turismo. Instituto Politécnico de Portalegre, Portalegre. $139 \mathrm{pp}$.

CABERo DiÉGUeZ, V. (1996): «Modelos de gestión y ordenación de los espacios naturales: ejemplos fronterizos», en Campesino, A.-J. y Velasco, C. (Coords.). PortugalEspaña: ordenación territorial del suroeste comunitario. Actas, ponencias y comunicaciones del VII Coloquio Ibérico de Geografía. Departamento de Geografía y Ordenación del Territorio. Universidad de Extremadura, Cáceres, pp. 410-419.

Cabero DiéGuez, V. (2002): Iberismo y Cooperación. Pasado y futuro de la Península Ibérica. Acto Académico de Apertura del Curso 2002-2003, Universidad de Salamanca, Secretaría General, Salamanca. 80 pp. 
CABo Alonso, A. (1989): «El paisaje del agua en Castilla y León», en Los paisajes del agua. Libro jubilar dedicado al profesor Antonio López Gómez. Universidad de Valencia-Universidad de Alicante, Valencia, pp. 109-120.

Cabo Alonso, Á. (1996): «Unidad geográfica en el Oeste de la Meseta y las zonas lusitanas inmediatas», en Campesino, A.-J. y Velasco, C. (Coords.). PortugalEspaña: ordenación territorial del suroeste comunitario. Caja Salamanca y Soria, Universidad de Extremadura, Cáceres, pp. 21-53.

CAmpesino FernándeZ, A.-J. (2001): «Territorio de frontera: adaptación, trazado y estructuras en la raya española», en Rossa, W.; Araujo; R.; CARITA, H. (Coords.). Atas do Colóquio Internacional. Universo Urbanístico Portugués, 1415-1822. Comissão Nacional para as Comemorações dos Descobrimentos Portugueses, Lisboa, pp. 751-767.

CAmpesino Fernández, A.-J. (Dir.). (2007): Turismo en la Raya ibérica: Situación actual y retos de futuro. Curso Internacional de Verano de la Universidad de Extremadura, Olivenza. (Inédito).

Campesino Fernández, A.-J. (Dir.). (2013): Turismo de Frontera (I). Rede Ibérica de Entidades Transfronteiriças (RIET), y Eixo Atlántico do Noroeste Peninsular, Vigo. 212 PP.

CAMPESIno Fernández, A.-J. (Dir.). (2014): Turismo de Frontera (II): Oferta y demanda turística en la Raya ibérica, Autores, Cáceres. 341 pp.

CAMPeSIno Fernández, A.-J. (2015): «Territorio y paisajes patrimoniales de la raya ibérica. El espacio geográfico de la EUROACE»/ Território e paisagens patrimoniais da raia ibérica. O espaço geográfico da EUROACE», en I Jornadas Internacionales sobre la Frontera Hispano-Portuguesa y sus Fortificaciones / I Jornadas Internacionais sobre a Fronteira Hispano-Lusa e as suas Fortificações. Proyecto Baluartes, Ayuntamiento de Badajoz, Badajoz, 2015, pp. 43-66.

Campesino, A.-J. y Jurado. J. M. (Dirs.). (2014): Turismo de Frontera (III): Productos turísticos en la Raya ibérica, Servicio de Publicaciones de la Universidad de Huelva, Huelva. 355 pp.

Campesino, A.-J. y Velasco, C. (Coords.). (1996): Portugal-España: Ordenación territorial del suroeste comunitario. Caja Salamanca y Soria, Universidad de Extremadura, Cáceres. 528 pp.

Cano Ramos, J. (2014): «El Tajo, un paisaje cultural en el Occidente europeo», en Lozano, M. ${ }^{a}$ del M. y Méndez, V. (Coords. y Eds.). (2014): Patrimonio cultural vinculado con el agua. Paisaje, urbanismo, arte, ingeniería y turismo. Editora Regional de Extremadura. Badajoz, pp. 65-84.

COLEGIO OFICIAL DE GEÓGRAFOS (2006): Manifiesto por una Nueva Cultura del Territorio. AGE, Madrid, 10 pp.

Cruz PARejo, E. (2014): «Patrimonio, naturaleza y agua: creando productos turísticos singulares en el Tajo Internacional», en Lozano, M. ${ }^{a}$ del M. y Méndez, V. (Coords. y Eds.). Patrimonio cultural vinculado con el agua. Paisaje, urbanismo, arte, ingeniería y turismo. Editora Regional de Extremadura. Badajoz, pp. 85-92.

DIRECCIÓN GENERAL DE ACCIÓN EXTERIOR. (2015): Mapa Turístico Alentejo, Centro, Extremadura EUROACE. Presidencia del Gobierno de Extremadura, 
Mérida. (Presentado por D. Enrique Barrasa Sánchez en la BTL de Lisboa, el 25 de febrero).

DIPUTACIÓN DE CÁCERES. (2006): Plan de Desarrollo Turístico del Parque Natural del Tajo Internacional., Cáceres. 148 pp.

DIPUTACIÓN DE CÁCERES. (2011): Taejo Internacional. Organismo Autónomo para el Desarrollo Local, Diputación de Cáceres, Indugrafic, Badajoz. 145 pp.

GARcía GonzÁlez, L. (1997): «Agua y Turismo en Extremadura. En espera de su consolidación como Producto Turístico», en Valenzuela M. (Coord.). Los turismos de interior. El retorno a la tradición viajera. Ediciones de la Universidad Autónoma de Madrid, Colección de Estudios, 52, Madrid, pp. 139-148.

Gil Olcina, A. (1996): «Usos conflictivos del agua en España», en Campesino, A.-J. y Velasco, C. (Coords.). Portugal-España: Ordenación territorial del suroeste comunitario. Caja Salamanca y Soria, Univ. de Extremadura, Cáceres, pp. 243-260.

Gonzalez Valve, J. L. (1985): «El Duero internacional». Anuario de Instituto de Estudios Zamoranos «Florián de Ocampo», 1984. Diputación Provincial de Zamora. Zamora, pp. 171-198.

HILDENBRAND SCHEID, A. (2010): Una estrategia de coherencia territorial para el Bajo Guadiana. Foro Internacional para el Desarrollo del Bajo Guadiana. Universidad Internacional de Andalucía, Sede de La Rábida. Consejería de Presidencia, Junta de Andalucía, Sevilla.

Hortelano Minguez, L. A. (1996): «El Espacio Natural de Arribes del Duero». Primeras Jornadas de Turismo Rural en Arribes del Duero. Caja Salamanca y Soria. Salamanca, pp. 131-151.

Hortelano Minguez, L. A. (2004): «El turismo en el valle del Duero/Douro. Una ruta temática jalonada de hitos naturales y culturales». En III Encontro Internacional: Relações Portugal-Espanha. O Vale do Douro no Ambito das Regiões Europeias (Zamora, 10-11 de octubre de 2002). Centro de Estudos da População, Economia e Sociedade (CEPESE). Porto.

Hortelano Mínguez, L. A. (Dir.). (2008): Atlas de la raya hispano-lusa: SalamancaBeira Interior Norte/Alto Douro. Diputación Provincial de Salamanca. Organismo Autónomo de Empleo y Desarrollo Rural; Salamanca. 223 pp.

Hortelano Mínguez, L. A. (Dir.). (2009): Atlas de la raya hispano-lusa: Zamora/ Trás-os-Montes. Diputación Provincial de Zamora, Salamanca. 224 pp.

Hortelano Mínguez, L. A. (2014): «Recursos naturales y turismo en la Raya castellano-leonesa», en Campesino, A.-J. (Dir.). Turismo de Frontera (II): Oferta y demanda turística en la Raya ibérica, Autores, Cáceres, pp. 11-32.

Hortelano Mínguez, L. A. (2014a): «Los productos turísticos en la «franja fronteriza» de Castilla y León con Portugal: la adaptación de los recursos y la interpretación territorial», en Campesino, A.-J. y Jurado. J. M. (Dirs.). Turismo de Frontera (III): Productos turísticos en la Raya ibérica, Servicio de Publicaciones de la Universidad de Huelva, Huelva, pp. 73-97.

Jurado Almonte, J. M. (Dir.) (2001): El turismo en el arco suratlántico-onubensealgarví. Consejería de Turismo y D., Junta de Andalucía, Sevilla. 214 pp. 
Jurado Almonte, J. M. (Dir.). (2011): Recursos, potencialidades y modelos turísticos en el Baixo Alentejo, Algarve y Provincia de Huelva. Servicio de Publicaciones, Universidad de Huelva, Huelva. 462 pp.

Jurado Almonte, J. M. (2013): «El turismo del marco onubense-algarví-alentejano en la cooperación transfronteriza de primera generación (1992-2013), en Campesino, A.-J. (Dir.). Turismo de Frontera (I). Rede Ibérica de Entidades Transfronteiriças (RIET), y Eixo Atlántico do Noroeste Peninsular, Vigo, pp. 119-129.

Jurado Almonte, J. M. (2014): «Patrimonio, recursos naturales y turismo en la franja fronteriza de la provincia de Huelva», en Campesino, A.-J. (Dir.). Turismo de Frontera (II): Oferta y demanda turística en la Raya ibérica, A. Cáceres, pp. 127-164.

Jurado Almonte, J. M. (2014a): «El turismo de frontera en la provincia de Huelva, de la potencialidad de sus recursos a destino y producto turístico», en Campesino, A.-J. y Jurado, J. M. (Dirs.). Turismo de Frontera (III): Productos turísticos en la Raya ibérica, Universidad de Huelva, Huelva, pp. 113-134.

Jurado, J. M. y Pazos, F. J. (2014): «Un recorrido por los paisajes del Bajo Guadiana», en Campesino, A.-J. y Jurado, J. M. (Dirs). Turismo de Frontera (III): Productos turísticos en la Raya ibérica, Universidad de Huelva, Huelva, pp. 323-355.

Lozano, M. ${ }^{a}$ del M. y MÉndez, V. (Coords. y Eds.). (2014): Patrimonio cultural vinculado con el agua. Paisaje, urbanismo, arte, ingeniería y turismo. Editora Regional de Extremadura. Badajoz. 404 pp.

Luna Martín, J. (2013): «El Plan de Competitividad Turística Guadiana Internacional», en Campesino, A.-J. (Dir.). Turismo de Frontera (I). Rede Ibérica de Entidades Transfronteiriças (RIET), y EANP, Vigo, pp. 149-152.

Márquez Domínguez, J. A. (2009): Atlas del Suratlántico Peninsular. Servicio de Publicaciones de la Universidad de Huelva.

Márquez Domínguez, J. A. (Dir.). (2012): Desarrollo de la frontera del Bajo Guadiana. Documentos para la Cooperación Luso-Andaluza. Servicio de Publicaciones de la Universidad de Huelva, Huelva. 55 pp. + CD.

MÁrquez Domínguez, J. A. (2012): «El perfil de la raya fluvial entre Andalucía y Portugal», en Márquez, J. A. (Dir.). Desarrollo de la frontera del Bajo Guadiana. Documentos para la Cooperación Luso-Andaluza. Servicio de Publicaciones de la Universidad de Huelva, Huelva, pp. 39-55.

MÁrquez Domínguez, J. A. (2014): «Oferta y demanda turística en la raya andaluza», en Campesino, A.-J. (Dir.). Turismo de Frontera (II): Oferta y demanda turística en la Raya ibérica, Autores, Cáceres, pp. 167-182.

Márquez, J. A.; Gordo, M.; Jurado, J. M. (2012): «Andalbagua y el I Foro Internacional para el Desarrollo del Bajo Guadiana», en Márquez, J. A. (Dir.). (2012): Desarrollo de la frontera del Bajo Guadiana. Documentos para la Cooperación Luso-Andaluza. Servicio de Publicaciones de la Universidad de Huelva, Huelva, pp. 19-36.

MAtA, R. y FernÁNDEZ, S. (2010): «Paisajes y patrimonios culturales del agua. La salvaguarda del valor patrimonial de los regadíos tradicionales», en Scripta Nova, Vol. XIV, n. ${ }^{\circ} 337,1$ de octubre. Barcelona. 
Medel Bermejo, J. L. (2013): «La cooperación transfronteriza de segunda generación en Extremadura (2014-2020). El parque natural Tajo Internacional», en Campesino, A.-J. (Dir.). Turismo de Frontera (I). Rede Ibérica de Entidades Transfronteiriças (RIET), y Eixo Atlántico do Noroeste Peninsular, Vigo, pp. 143-148..

Melgosa Arcos, F. J. (Coord.). (2013): Turismos de interior. Planificación, comercialización y experiencias. Ediciones Pirámide, Colección Economía y Sociedad, Madrid. 508 pp.

Padín, C. y Pardellas, X. X. (2014): «Potencialidades del turismo de frontera y uso de los recursos turísticos en Galicia», en Campesino, A.-J. (Dir.). Turismo de Frontera (II): Oferta y demanda turística en la Raya ibérica, Aut., Cáceres, pp. 33-46.

Pardellas de Blas, X. X. (2013): «Turismo en regiones de frontera: Galicia», en Campesino, A.-J. (Dir.). Turismo de Frontera (I). Rede Ibérica de Entidades Transfronteiriças (RIET), y Eixo Atlántico do Noroeste Peninsular, Vigo, pp. 61-68.

Pardellas, X.; Padín, C.; Ayude, J. (2014): «El turismo como factor potencial de desarrolla entre Galicia y el Norte de Portugal: usos conjuntos del río Miño», en en Campesino, A.-J. y Jurado, J. M. (Dirs). Turismo de Frontera (III): Productos turísticos en la Raya ibérica, Universidad de Huelva, Huelva, pp. 135-161.

RENGIFO, J. I. y JimÉNEZ, V. (2014): «Conservación de espacios y raya luso-extremeña: una asociación bien avenida», en Campesino, A.-J. (Dir.). Turismo de Frontera (II): Oferta y demanda turística en la Raya ibérica, A., Cáceres, pp. 47-82.

Ribas Palom, A. (2006): "Los paisajes del agua como paisajes culturales. Conceptos, métodos y experiencias prácticas para su interpretación y valorización». Artículo en versión adaptada de la ponencia «Naturaleza y cultura en la creación y valorización de los paisajes del agua», impartida por el autor en el VII Coloquio Ibérico sobre Planificación y Gestión del Agua. Faro, 4 a 8 de diciembre.

Ribeiro Da Cunha, O. (1980): Geografía e Civilização. Livros Horizonte, 2. Espaço e Sociedade. Lisboa. 161 pp. + fotografías.

SÁnchez Martín, J. M. (2014): «Aplicaciones geoestadísticas en entorno Sig, como soporte para la planificación turística. El caso de la frontera luso-extremeña», en Campesino, A.-J. y Jurado, J. M. (Dirs). Turismo de Frontera (III): Productos turísticos en la Raya ibérica, Universidad de Huelva, Huelva, pp. 241-270.

SÁnchez Rivero, M. (2014): «Mercados turísticos en el ámbito transfronterizo extremeño: los casos del Tajo Internacional y de Alqueva», en Campesino, A.-J. y Jurado, J. M. (Dirs). Turismo de Frontera (III): Productos turísticos en la Raya ibérica, Servicio de Publicaciones de la Universidad de Huelva, Huelva, pp. 163-182.

Unamuno, M. de (1998): Los Arribes del Duero. Iberdrola, Salamanca.

Valenzuela Rubio, M. (Coord.). (1997): Los turismos de interior. El retorno a la tradición viajera. Ediciones de la Universidad Autónoma de Madrid, Colección de Estudios, 52, Madrid. 